\title{
RELIGIÃO E IDENTIDADE CULTURAL NA PEREGRINAÇÃO DE FERNÃO MENDES PINTO
}

\author{
RELIGION AND CULTURAL IDENTITY IN PEREGRINAÇÃO BY FERNÃO MENDES
}

PINTO

\author{
Luís André Nepomuceno \\ Universidade Estadual de Campinas
}

RESUMO: $O$ artigo pretende rastrear na Peregrinação, de Fernão Mendes Pinto os episódios que envolvem conflitos religiosos ou conflitos políticos decorrentes de motivações religiosas. Além do ódio entre cristãos e muçulmanos, outros planos se evidenciam na narrativa, especialmente a ideia da religião como convergência de interesses e identificação cultural e política entre indivíduos. Diante desse contexto, o trabalho evidencia Mendes Pinto como escritor humanista, capaz de perceber no cenário político e religioso do séc. XVI um palco para o teatro das presunções, em que as verdades teológicas se pulverizam e se relativizam, e em que cada um atribui a si a boafé e, ao outro, a ignorância e a barbárie.

PALAVRAS-CHAVE: Renascimento português; Fernão Mendes Pinto; literatura e religião; identidade cultural.

\begin{abstract}
The paper intends do track in Fernão Mendes Pinto's Peregrinação the incidents that involve religious conflicts or political conflicts deriving from religious motivations. Besides the hatred among Christians and Muslims, other outlines are evident in the narrative, especially the idea of religion as a convergence of interests as well as cultural and political identification among individuals. Considering this background, the paper evinces Mendes Pinto as a humanist writer, able to perceive in the 16th century political and religious scenery a kind of stage for the theater of arrogances, in which the theological truths are reduced to dust and become relative, and in which each one attributes to himself the good faith, and to the other ones, ignorance and barbarity.
\end{abstract}

KEYWORDS: Portuguese Renaissance; Fernão Mendes Pinto; literature and religion; cultural identity.

É possível que muitos leitores da Peregrinação, de Fernão Mendes Pinto, vão concordar que, entre os episódios mais enternecidos da imensa coletânea de histórias sobre o Oriente, estão aqueles em que cristãos reconhecem correligionários em meio às sociedades orientais, quando a visão da cruz se mistura à alegria exaltada (e clandestina) de ver no outro a raiz de sua pátria e identidade. No capítulo 91, por exemplo, vemos os nove portugueses sobreviventes do naufrágio de 1542 encontrar em Sampitay, na China, 


\section{Revista do SELL}

V. 5 , No. 4

ISSN: $1983-3873$

ao longo da amarga experiência do cárcere, a nobre e gentil Inês de Leiria, cristã nascida no exílio, filha de Tomé Pires, um dos embaixadores enviados à China entre 1518-1521. Inês reconheceu os portugueses e os levou a sua casa, e assim "mostrou hum oratorio em que tinha huma Cruz de pao dourada, com huns castiçais \& huma alampada de prata" (Alves, 2010, vol. II, cap. 91, p. 297)1․ Depois será a vez de Vasco Calvo, também exilado e outro dos embaixadores enviados à China, na frustrada missão do começo do século. A exemplo de Inês de Leiria, Vasco leva os portugueses a sua casa, onde a esposa os recebe, e onde, depois do jantar, em meio a incertezas e apreensões, clandestinamente "tirou uma chaue que trazia no braço, \& abrio huma portinha de hum oratorio muyto bem concertado, onde estaua hum altar com huma Cruz de prata, \& dous castiçaes \& huma alampada do mesmo" (Per. 116, p. 385). E então os portugueses, saudosos da pátria, em meio às lágrimas, fazem uma oração tocada de um sentimento elevado, prometendo viver na "santissima Fe Catholica como bons \& verdadeyros Christãos".

Não são apenas os encontros comoventes com irmãos correligionários que movem o reconhecimento e a identidade pátria por meio da religião, mas também as notícias da cristandade que se espalham aqui e ali, pelas muitas terras do Oriente. Ainda no interior da China, junto às ruínas de uma cruz numa cidade fictícia, o narrador nos dá notícia de um santo homem estrangeiro, "húngaro de nação" e ermitão no Monte Sinai, um certo Mateus Escandel, que, em meio às provocações dos religiosos chineses, ressuscitara cinco mortos e fizera outras maravilhas ${ }^{2}$. Escandel pregara a verdade de Cristo e fora morto a pedradas pela comunidade religiosa local, mas as pegadas de seu esforço causaram "grandíssima admiração", levando o narrador a dizer, comovido, que "faltão palavras para dizer o que Deos nosso Senhor aly nos deus a sentir" (Per. 96, p. 314). Muito depois, acompanhando a comitiva do rei de Bramá pelas terras do Calaminham (Laos), o narrador vai uma vez mais dar notícia de um certo Tomé Modeliar, cujo discípulo João viera ter àquele reino pregar que "Deos se fizera homem, \& morrera pelos homens" (Per. 164, p. 560), história narrada por um grepo (monge siamês) que ouvira falar de Adão

\footnotetext{
1 Daqui em diante, todas as citações da Peregrinação serão extraídas da edição de Jorge Santos Alves, referenciando-se o número do capítulo e da página.

${ }^{2}$ A respeito do personagem, Mateus Escandel é "probably a Jew, being Escandel Pinto's corruption of Iskandar (Alexander)": ALVES, 2010, vol. III, nota 13, p. 125.
} 


\section{Revista do SELL}

V. 5 , No. 4

ISSN: $1983-3873$

e Eva, e de Noé, mas não conhecia a história de Cristo, uma lenda que ele ouve mas de que duvida.

Na Peregrinação, imenso livro de histórias sobre a Ásia Extrema, volume resultante das viagens de seu autor pelo Oriente entre 1537-1558, e publicado postumamente em 1614, não apenas os portugueses, porém todos os personagens se distinguem e se reconhecem por sua identidade religiosa, o que significa que todos eles "observam o que os rodeia com base em princípios religiosos; e por isso é motivo de alegria sempre que se encontram entre pares que partilham a mesma ideologia" (Tavares, 2008, p. 15). Mais do que a motivação política ou econômica, o que identifica e une os personagens é um sentimento de pertença religiosa, uma vez que cada um deles enxerga no outro a exclusão de sua verdade revelada. Para o narrador, gentios e muçulmanos serão sempre a legítima representação da "maldita seita", e mesmo para os gentios, cristãos serão igualmente "bárbaros [que] carecem do perfeito conhecimento da nossa verdade" (Per. 102, p. 334).

Mesmo a Europa dando início a um lento processo de laicização da sociedade, da política e do conhecimento, os princípios da era moderna, em meio às batalhas ferozes entre cristãos, muçulmanos e gentios na disputa do comércio nos mares do Índico, verão florescer um confronto que, embora motivado por interesses econômicos, terá sua raiz também na composição híbrida dos estados e impérios religiosos. A julgar pelo cenário de barbárie e atrocidades estampado na Peregrinação, o fanatismo e a violência serão a moeda de troca entre estranhos que não partilham da mesma comunidade religiosa ${ }^{3}$.

A par das narrativas comoventes de encontros entre cristãos, o livro de Fernão Mendes Pinto nos revela, por outro lado, a face cruenta no encontro com a diversidade e com a suposta traição às comunidades religiosas, gravada na face dos "renegados". Bem no princípio da saga de viagens, por exemplo, o narrador (que a esse ponto ainda não trabalha para o bando de corsários de Antonio de Faria) nos fala do capitão de uma nau, com quem os portugueses tiveram um desentendimento, e que depois se revela "Christão renegado, Malhorquy de nação, natural de Cerdenha, filho de um mercador que se

\footnotetext{
${ }^{3}$ Identifico o fanatismo, a partir do conceito de Jaime Pinsky e Carla B. Pinsky, para quem o termo significa "a exaltação que leva indivíduos ou grupos a praticar atos violentos contra outras pessoas (prejudicando significativamente sua liberdade e atentando contra a vida), baseados na intolerância e na crença em verdades absolutas, para as quais não admitem contestação": Pinsky\& Pinsky, 2004, p. 11.
} 


\section{Revista do SELL}

V. 5 , No. 4

ISSN: $1983-3873$

chamaua Paulo Andrès, \& que não auia mais que sós quatro anos que se tornara Mouro por amor de huma grega Moura com que era casado" (Per. 3, p. 35). Os capitães portugueses ainda procuram trazer de volta o capitão à fé cristã antes de sua morte, mas ele se recusa com veemência, motivo pelo qual é lançado ao mar com um penedo ao pescoço, "donde o diabo o leuou a participar dos tormentos de Mafamede em que tão crente estaua [...]" (Per. 3, p. 35-36)4. Seguindo o mesmo caminho, o capítulo 46 também nos dá a conhecer um corsário igualmente renegado, Necodá Xicaulem, falsamente convertido ao cristianismo com o nome de Francisco de Sá, e casado com uma mulher cristã, que ele matara. Necodá vinha trazendo na sua embarcação uma comitiva de cativos cristãos, entre homens e mulheres, todos acorrentados e maltratados, alguns deles nus e doentes. Para os renegados como Necodá, a lei se cumpre outra vez: portugueses cortam-Ihe a cabeça, e o fazem em pedaços.

Por outro lado, virão ainda os convertidos de última hora, ou os cristãos vivendo entre mouros e gentios, como fossem parte deles, porém mantidos na fé, todos admitidos e adotados na comunidade religiosa cristã como iguais. Na volta do reino de Aaru, junto à ilha de Sumatra, o narrador e toda uma comitiva de embaixadores e estrangeiros naufragam e se veem às vascas da morte, em fome, sede e doença, quando um deles, muçulmano, se abraça ao narrador, pedindo-lhe com lágrimas que "logo o fizesse Christão, porque entendia, \& assi o confessaua que só com o ser se podia saluar, \& não na triste seita de Mafamede, em que ate então viuera, de que pedia a Deos perdão" (Per. 23, p. 89). Será o único a receber sepultamento, o melhor que puderam. A mesma tolerância se dará com um cafre (negro africano), cujo traseiro é mostrado aos portugueses de uma comitiva, no mar, como forma de provocação, o que gera um confronto e uma batalha sangrenta, quando Antonio de Faria, em vencendo a disputa, põe a tormento e tortura um bando de achéns e turcos da nau inimiga, poupando o referido cafre, que se diz cristão, e a quem o capitão português oferece biscoitos e vinho (Per. 40).

O sentimento de pertença à comunidade religiosa, somado ao exercício do preconceito e da intolerância, será a motivação inicial para a aproximação entre iguais e para o cultivo do ódio entre dessemelhantes. Carlos Jorge, em curioso ensaio sobre as

\footnotetext{
${ }^{4}$ Hernani Cidade comenta que o narrador "considera zelo santo da honra de Deus atar de pés e mãos a um renegado que não queria voltar à Fé”: Cidade, 1963, vol. I, p. 107 [grifos do autor].
} 


\section{Revista do SELL}

V. 5, No. 4

ISSN: $1983-3873$

práticas de pirataria no Índico em meados do século XVI, chega a pontuar que a imagem do pirata, tão forte era a sua identificação com os anseios religiosos, que parecia associada ao próprio exercício da religião, como uma espécie de cruzada (JORGE, 1999, p. 79). "Diz-me qual é a tua religião e dir-te-ei a maneira como te vou combater e liquidar", considera, com perspicácia, o historiador Alfredo Margarido, a respeito das relações conflituosas entre estranhos no Índico, durante a expansão do império português (Margarido, 1991, p. 1003).

O cenário histórico daqueles meados de século mostra que as rivalidades religiosas espelhavam interesses econômicos e demarcações de fronteiras políticas, numa situação que bem define a total ausência de limites entre o estado e a religião. Francisco Xavier, por exemplo, o apóstolo do Oriente, jesuíta evangelizador do Japão e da Índia, cujos trabalhos de catequese foram registrados na Peregrinação, teve de se opor duramente aos preconceitos contra "renegados" hindus, quando de seu trabalho na Índia, a exemplo do que vinha acontecendo contra "renegados" cristãos no livro de Mendes Pinto. Em 1544, enquanto formava comunidades católicas de convertidos em massa e dava ordens para destruir templos e imagens sacras do hinduísmo, Francisco escreveu do interior da Índia pelo menos umas 20 cartas desesperadas a Francisco Mancias, também ele padre jesuíta, informando-lhe sobre a trágica situação dos convertidos hindus, perseguidos por um grupo fanático local que se pôs à destruição das práticas católicas e dos próprios convertidos. "Muitos morrem miseravelmente de fome e de sede no meio das rochas ao longo do Cabo Camorim", ele diz numa epístola (Coleridge, 1872, vol. I, p. 212). Em setembro daquele ano, um Comandante nativo vê sua embarcação e sua casa queimadas, enquanto tentava ajudar os hindus convertidos, tidos como renegados do hinduísmo: "ele renunciou a toda amizade comigo numa carta cheia de ataques ferozes", complementa o Padre Xavier. "O que Francisco tenta instaurar na costa da Pescaria entre 1542 e 1544 é uma utopia social”, assegura um de seus biógrafos (Didier, 1996, p. 47).

O que não sobrevém à consciência de Francisco Xavier é que, também para gentios e muçulmanos, o que definimos no cristianismo como "verdade revelada" é um distintivo cultural e político que ocorre analogamente em outras religiões, uma espécie de herança vinculada a antigas promessas comunitárias que definem a pertença e o vínculo 


\section{Revista do SELL}

V. 5 , No. 4

ISSN: $1983-3873$

identitário do indivíduo. O renegado, portanto, é aquele que rompeu com a promessa e com a verdade revelada, um traidor da comunidade e dos vínculos políticos, já que Deus destina a determinado povo seu conhecimento, sua proteção e sua aliança. Se o apóstolo jesuíta levava aos gentios a única verdade revelada, esquecia-se de que em Malaca, por exemplo, os nativos já eram convertidos muçulmanos, para quem a revelação do profeta era uma realidade política e religiosa consolidada. Para judeus, a cabala é uma revelação do povo eleito, inalcançável às demais comunidades. Até mesmo para os gentios chineses, num dos capítulos da Peregrinação, aquele bando de mendigos portugueses "carecem do perfeito conhecimento da nossa verdade" (Per. 102, p. 334).

Nesse contexto, portanto, o outro só se torna efetivamente o outro, como indivíduo estranho e exótico, porque não crê no que crê aquele que o observa, e esse pressuposto definiu radicalmente os princípios da soberania religiosa e do estranhamento das crenças alheias. A respeito dos bonzos (os sacerdotes budistas do Japão), Luís Fróis, jesuíta e missionário, dizia com segurança: "nós sobre todas as cousas avorrecemos e abominamos ao demónio; os bonzos o veneram e adoram e lhe fazem templos e grandes sacrefícios" (Fróis, 1993, p. 91). À vista de um desentendimento absoluto das enigmáticas crenças gentias no mundo oriental por parte de missionários católicos, e a julgar igualmente por um desinteresse completo por esses novos costumes e "verdades reveladas", a demonização foi uma prática comum de jesuítas em relação a muçulmanos e gentios. Para Francisco Xavier, por exemplo, Goa, a capital do império português no Oriente, e para onde ele solicitaria com urgência um tribunal da Inquisição, era o espelho inequívoco do próprio reino de Satã ${ }^{5}$.

Portanto, a considerar o cenário histórico da Peregrinação, numa época em que diversos impérios se expandiam em busca do comércio no Oriente, Mendes Pinto coloca em cena uma espécie de teatro das presunções, em que as verdades teológicas se pulverizam e se relativizam, e em que cada um atribui a si a boa-fé e o pertencimento à verdade revelada, e ao outro, a ignorância, a barbárie e o desconhecimento de sua verdade, que é e sempre foi a promessa de seu Deus. Esse teatro das presunções (a presunção da verdade, da revelação e do pertencimento) é, na prática, um exercício do

\footnotetext{
5 "[...] the images to which he [Xavier] constantly refers point to a unique imaginary on the author's part, a cosmological vision in which Goa, its jungle, and India are likened to the kingdom of Satan, and its inhabitants to the flying devils of the underworld" (Conrod, 2012, p. 97).
} 


\section{Revista do SELL}

V. 5, No. 4

ISSN: $1983-3873$

poder e uma justificativa, humana e divina, bem como uma legitimação política para a guerra, a violência e a dizimação dos infiéis. Jogar ao mar, com um penedo amarrado ao pescoço, um renegado cristão que se recusou à reconversão que se the oferecia, é quase uma atitude de revanchismo e uma prática explosiva do ódio contra a infidelidade, ainda que disfarçada de salvação da alma na hora da morte, no caso das atitudes análogas da Inquisição.

A julgar por esse exclusivismo na comunhão e nas práticas identitárias das sociedades do seu tempo, Mendes Pinto põe à vista, na Peregrinação, um complexo painel de confrontos religiosos, em que revela a concepção de um Deus particularista e providencialista almejado pela visão de cada indivíduo. É como se o Deus do outro estivesse embrenhado nos seus propósitos de guerra e na sua concepção mesma de mundo e de sociedade. Assim sendo, é altamente emblemático o episódio, passado na Tartária, em que o narrador observa uma cena atípica num palácio do rei da Cochinchina: oitenta e três estátuas de deuses em bronze, todas presas pelos pescoços com cadeias de ferro. Eram as imagens sagradas de inimigos conquistados pelo rei, tomadas de um grande templo onde estavam, "porque a mayor honra, \& de que el Rey fazia mayor caso, era triumphar dos deoses de seus inimigos, que a despeito trazia catiuos" (Per. 130, p. 429). No capítulo seguinte, assistimos à entrada triunfal do rei na cidade conquistada, trazendo cativos os sacerdotes da gente inimiga, "os quais todos hião chorando", acompanhados dos ídolos em bronze expostos no palácio. Em outros termos, o que Mendes Pinto mostra, com o episódio, é a força simbólica do próprio Deus inimigo como espólio de guerra, dentre tantos outros espólios que vencedores ostentavam depois de suas vitórias (terras, posses, mulheres), sugerindo que trazer o Deus do inimigo como cativo significa aprisionar, ao mesmo tempo, todo um corpo doutrinário de concepções históricas, messiânicas e religiosas que o inimigo carrega consigo como herança cultural. É o sinal de sua derrota completa. Não é por um raciocínio tão diverso que Francisco Xavier, na Índia, dirigia "grupos de jovens encarregados de destruir ou profanar com escarro ou excremento os ídolos hindus ainda adorados pelos pescadores tornados cristãos" (Didier, 1996, p. 47). Sim, toda prática destrutiva e iconoclasta da crença do outro, ou toda manutenção de seus símbolos religiosos em regime de cativeiro, serão 


\section{Revista do SELL}

V. 5, No. 4

ISSN: $1983-3873$

ostentadas em nome de um Deus particularista, a guiar com mãos providenciais o destino de seus eleitos.

A religião, portanto - incluída aí a sua herança cultural, política e messiânica -, torna-se um verdadeiro instrumento e uma razão motivacional de guerra, em defesa não apenas de um Deus individualista, mas também de sua legitimidade e do pacto social que ela implica. Uma vez que os portugueses, logo nos primórdios da expansão de seu império, davam mostras notórias de defender os interesses de Deus e da cristandade, eles receberam, já no séc. $\mathrm{XV}$, pelo menos três bulas papais, validando e legitimando conquistas, e a primeira delas, a Dum diversas, de 1452, autorizava o rei de Portugal a "atacar, conquistar e submeter sarracenos, pagãos e outros descrentes inimigos de Cristo; a capturar seus bens e territórios; a reduzi-los à escravatura perpétua e a transferir as suas terras e territórios para o rei de Portugal e para os seus sucessores" (Boxer, 2012, p. 38). Ainda que as motivações religiosas se vissem misturadas a interesses econômicos, cumpre dizer que os portugueses estiveram seriamente preocupados com a conversão dos outros povos, especialmente a partir de 1540, quando da chegada dos jesuítas no Oriente. Na destruição de deuses e templos alheios, para a edificação de igrejas, ocorre igualmente que "esta sobreposição de espaços religiosos é uma boa metáfora para a convicção de que uma mudança de religião é uma consequência natural da ocupação do espaço pela conquista militar" (Sá, in: Bethencourt, 2010, p. 265).

Em resumo, pode-se dizer que nesse "teatro das presunções", trágico cenário religioso da Peregrinação, gentios, cristãos, budistas e muçulmanos - uma vez confrontados com a nova realidade das navegações e com o súbito contato entre culturas distintas - têm cada um deles uma espécie de Deus particularista e providencialista, vinculado a promessas religiosas e a heranças políticas, bem como ao cultivo do ódio contra o estrangeiro, e que a destruição ou aprisionamento do Deus alheio implicará igualmente a consolidação simbólica de uma vitória militar.

Será preciso lembrar que, a par da violência entre comerciantes, missionários e corsários no Oceano Índico do séc. XVI, pelo menos dois grandes impérios - o português e o otomano - mantiveram políticas de expansão e consolidação territorial, bem como práticas constantes de sujeição religiosa a seus conquistados. Um historiador pontua que justamente por causa de sua iniciativa de converter à sua fé um quinto da humanidade é 


\section{Revista do SELL}

V. 5 , No. 4

ISSN: $1983-3873$

que o islamismo "terminou por conflitar-se com o cristianismo, nascido igualmente na mesma região e tendo as mesmas ambições de conversão universal” (Schilling, 2006, p. 22).

Uma boa parte do livro de Mendes Pinto, especialmente os episódios envolvendo os confrontos de Antonio de Faria e os corsários mouros, retrata o conflito milenar entres cristãos e muçulmanos, agora expostos a circunstâncias históricas muito bem definidas: o embate entre o império português e o império turco-otomano nos mares do Índico, tendo como princípio e motivação, de ambos os lados, a política de expansão imperialista e o projeto de conversão dos povos subjugados. Ivo Carneiro de Sousa mostra que os portugueses, desde o séc. $\mathrm{XV}$, vinham reagindo retoricamente, porém não belicamente, à expansão do império otomano, propondo alianças e alternativas para a renovação da Igreja na luta contra os "turcos", essa denominação genérica que, além de reduzir as complexidades nacionais e étnicas do império otomano, reduzia-os a uma comunidade de bárbaros e infiéis (Sousa, 2003, pp. 567-579). Portugueses e turcos otomanos vão se encontrar e digladiar apenas no século seguinte, cada um deles reagindo com atrocidade e violência às intenções imperialistas do outro.

A história mostra que, na primeira expansão do imperialismo islâmico, não imperou o proselitismo que havia de caracterizar, por exemplo, as missões católicas no Oriente, nem as políticas obsessivas de conversão dos povos subjugados. No que diz respeito a práticas de intolerância ou convivência entre dessemelhantes, cristãos mostraram-se prosélitos e bem mais preocupados em propor a relação entre a sujeição religiosa e o domínio político (Armstrong, 2002, p. 102). Pelo menos em tese, e a julgar pela máxima do Alcorão de que não deve haver compulsão religiosa no Islã, conforme determinavam Maomé e a Constituição de Medina, os muçulmanos não estiveram tão obstinados quanto cristãos no combate das infidelidades ${ }^{6}$, mas por contradição, deve-se entender ainda que os árabes, e posteriormente, os grandes impérios islâmicos, como o otomano, viam na expansão política e religiosa uma necessidade de lutar contra o infiel, numa espécie de jihad perpétuo ${ }^{7}$.

\footnotetext{
${ }^{6}$ Ver, por exemplo, Lewis, 2010, p. 104-105 e Schilling, 2006, p. 22.

${ }^{7}$ A respeito da luta do império islâmico contra o infiel, um historiador afirma: "Equally, if not more, important was to drive towards existence as a great state, identifiable with the Arabs. It derived its moral justification from the Koran, in the summons to fight the unbeliever" (Grunebaum, 2006, p. 53).
} 


\section{Revista do SELL \\ V. 5 , No. 4 \\ ISSN: $1983-3873$}

Quando os turcos otomanos criaram seu vasto império, abalando as bases da Europa e deixando os cristãos alvoroçados e temerosos de seu poder, sua luta contra os infiéis era também uma realidade incômoda. Karen Armstrong esclarece que nunca a Shariah (ou lei islâmica, em seu sentido mais fundamental) desempenhara papel tão destacado quanto no Império Otomano, com suas raízes fincadas na fidelidade à lei e aos princípios fundamentais da existência, o que demandaria uma luta e um esforço (jihad) em todos os âmbitos: espiritual, político, social, pessoal, militar e econômico (Armstrong, 2001, p. 56). Ao longo do tempo, o Islã desenvolveu, a exemplo do que o Cristianismo vinha fazendo, uma espécie de teoria coerente da guerra, desde que ela fosse destinada a uma causa pia. O grande jihad, ou a luta interna contra o mal e a tentação, que os cristãos definiriam como guerra santa contra o pecado, converteu-se no pequeno jihad, ou batalha militar contra os inimigos infiéis e em favor da expansão da verdade revelada do profeta (Wheatcroft, 2004, p. 211).

Tudo isso equivale a dizer que portugueses e otomanos, ao se atirarem às navegações no Índico, visando o comércio com a Ásia Extrema, nos princípios da era moderna, mostraram-se rivais também nos domínios da religião e do proselitismo, cada um trazendo consigo o seu Deus particularista e suas promessas messiânicas, e enxergando no outro o seu objeto de demonização.

$\mathrm{Na}$ Peregrinação, de Mendes Pinto, os princípios vitais da cruzada e do pequeno jihad se veem frente a frente nos mares do Oriente e se enfrentam com violência e atrocidade, seja pelo providencialismo divino, seja pela necessidade de vingar os renegados, seja pelo simples cultivo do ódio contra as diferenças que, àquele momento, significavam ao mesmo tempo também as rivalidades políticas e econômicas. Antonio de Faria, historicamente o capitão de Malaca, escudeiro fidalgo da nobreza de seu tempo, recebido com apoteose no porto de Liampó, depois de sua vitória contra Coja Acém (Per. 68-69), embora contraditoriamente um temido corsário nos mares da China, será a representação da consciência política e religiosa portuguesa e a convergência de seus ideais. Entre os capítulos 36-79, comanda um bando de piratas seus conterrâneos, travestidos de mercadores, vivendo à margem da lei, saqueando vilas, pilhando tesouros e matando nativos civis inocentes, porém vivendo, como "homem bom Christão, como na verdade o era" (Per. 60, p. 202), conforme o define o narrador. Se por "homem bom 


\section{Revista do SELL}

V. 5, No. 4

ISSN: $1983-3873$

cristão" se entende a disposição bélica para o espírito da cruzada, Antonio de Faria será, portanto, a síntese das contradições entre violência e pregação religiosa, ou ainda, o distintivo da identidade cultural somado aos anseios da religião como instrumento de guerra. Generoso para com os cristãos, pregador habilidoso nas horas amargas (lembrese a Ilha dos Ladrões), Faria é o resultado de uma lenta e complexa elaboração histórica, e seu brado de guerra na luta contra Coja Acém ("Christãos e senhores meus, se estes se esforção na maldita seita do diabo, esforcemonos nós em Christo nosso Senhor posto na Cruz": Per. 159, p. 198) traz à memória um acervo imenso de rancores e ressentimentos atávicos em favor de um Deus providencialista e do imperialismo político a ele relacionado. Seu clamor terá um eco na exortação de Francisco Xavier, quando este convoca mercadores para lutarem contra turcos achéns que torturaram cristãos em Malaca, cortando-lhes narizes e orelhas: "Ora sus irmãos \& senhores meus, não vos entristeçais, porque vos afirmo que Deos nosso Senhor he com nosco, \& de sua parte vos requeyro que nenhum se negue a yr nessa santa jornada, porque elle nos manda que assi o façamos" (Per. 203, pp. 701-702).

No longo episódio de Antonio de Faria, que ocupa quase a quinta parte do livro, o mercador e corsário sai pelos mares da China, deixando atrás de si um rastro de sangue, em luta contra inimigos mouros, ou chineses convertidos à fé muçulmana, como Coja Acém, Similau, Hinimilau, Prematá Gundel ou Heredim Mafamede, sempre pelejando "com muyto esforço, \& tanto sem piedade quanto requeria o odio com que pelejauão", conforme nos diz o narrador, quando da luta contra os turcos achéns (Per. 206, p. 712).

Depois, em partes centrais da Peregrinação, antes da narrativa de Francisco Xavier na catequese do Japão, virão os confrontos entre gentios e cristãos, ou entre gentios e eles mesmos, quando, então, o ódio religioso da primeira parte, resultado de heranças políticas e de ressentimentos ancestrais contra judeus e muçulmanos, dá espaço a combates de natureza mais essencialmente política e imperialista. Mercadores e missionários cristãos ainda não haviam avolumado seus rancores contra budistas, confucionistas, hinduístas e pagãos de toda espécie, essa massa de gente desconhecida que, pelo menos no olhar excitado dos primeiros jesuítas, mostrava-se aberta e favorável às grandezas da nova fé. "Ouvi dizer que há uma ilha na Índia inteiramente povoada de pagãos, sem qualquer mistura de muçulmanos e judeus", escreve o animado Francisco 


\section{Revista do SELL}

V. 5 , No. 4

ISSN: $1983-3873$

Xavier aos amigos da Companhia de Jesus em Lisboa, em 1541, acrescentando sua máxima esperança de bons frutos naquela terra idealizada (Coleridge, 1872, vol. I, p. 90). Em outras partes centrais da Peregrinação, Mendes Pinto impressiona-se com o fanatismo e a devoção irrestrita de certos gentios, como os peregrinos do templo de Tinagogó, que se martirizam e cometem suicídio nos altares do grande deus, mostrando aos cristãos "o muyto que estes miseraueis fazem por se perderem, \& o pouco que os mais dos Christãos fazemos por nos saluarmos" (Per. 161, p. 542) ${ }^{8}$.

Muito se tem dito sobre a posição política e religiosa de Fernão Mendes Pinto. Rebecca Catz, leitora norte-americana da Peregrinação, garante que aquele sacerdote em Calaminham que afirma que Deus não poderia encarnar na matéria, porque rubi de tão alto quilate não pode se criar na terra, seria a própria voz de Mendes Pinto, descrente com o cristianismo e sua dogmática (Catz, 1981, p. 91). Francisco Ferreira de Lima replica a autora, deixando claro que a voz do narrador é a voz mesma de Mendes Pinto, o cristão fiel e intolerante para quem o cristianismo continua sendo uma verdade inconteste e as seitas orientais, um amontoado de patranhas; o cristão que anseia pela depuração dos costumes, seja na reforma moral da Igreja, seja na luta contra o mouro (Lima, 1998, p. 112-113, e 128-129).

Ambas as teses soam um tanto controversas. Sabe-se que a mais famosa estratégia de Mendes Pinto é admoestar com veemência a atitude do homem oriental, e fazer com que o homem oriental censure os portugueses, num curioso jogo de vozes que se alternam. Na ilha de Ainão, Antonio de Faria ataca e mata nativos mouros inocentes, acreditando perseguir o seu inimigo Coja, e depois recebe uma aguda censura de um mouro, dizendo-lhe que o que faz "não he muyto conforme â ley Christam que no bautismo professaste" (Per. 42, p. 143). Por outro lado, não censurar Antonio de Faria por ter atirado ao mar o renegado cristão é uma prática comum do narrador do livro, porque Mendes Pinto frequentemente se abstém das críticas a seus conterrâneos, embora não se abstenha de narrá-las. Mas ao apontar a fatuidade das crenças e o ódio movido pelas guerras santas, nesse teatro das presunções, o livro de Mendes Pinto parece longe de

\footnotetext{
${ }^{8}$ G. Le Gentil nos informa que Tinagogó só pode se referir a um lugar imaginário, onde Mendes Pinto teria fabulado sua dramática narrativa de suicídios, ainda que notícias de sacrifício e martírio viessem comumente à Europa desde Marco Polo: "Nous croyons plutôt qu'il tient son récit d'un marchand du Bengale, puisqu'il prétend avoir été à Chittagong. La coutume du suicide religieux était du reste parfaitement connue des Européens depuis Marco Polo" (Le Gentil, 1947, p. 60).
} 


\section{Revista do SELL}

V. 5 , No. 4

ISSN: $1983-3873$

validar a ação católica portuguesa no Oriente. A Peregrinação revela que o reconhecimento entre correligionários no exílio pode fazer aflorar um profundo sentimento de pertença social, mas a exposição da imagem da religião como instrumento de guerra mostra que as verdades teológicas se pulverizam e se relativizam, num espetáculo de intolerância, violência e barbárie.

Mendes Pinto pode não ter deixado de ser cristão, depois de sua experiência de 21 anos no Oriente (como o quer Rebecca Catz), mas por certo, deve ter aprendido que, em meio às particularidades e ao providencialismo do Deus de cada religião, gentios podem ser sábios, e católicos podem ser cruéis na sua fé. Um certo rei de Patane, no capítulo 220, referindo-se à comitiva de Belchior Nunes Barreto que busca a China para levar o Evangelho, acredita que aquilo tudo não passa de um amontado de parvoíces. Em outros termos, a exclusividade de seu Deus lhe garante que aquela "gente do cabo do mundo" não fizera o pacto, único e verdadeiro, que em Patane se fizera entre os eleitos.

\section{Referências}

ALVES, Jorge Santos (dir.). Fernão Mendes Pinto and the Peregrinação: studies, restored Portuguese text, notes and indexes. Lisboa: Fundação Oriente/ Imprensa Nacional-Casa da Moeda, 2010 (4 vols.).

ARMSTRONG, Karen. Em nome de Deus: o fundamentalismo no judaísmo, no cristianismo e no islamismo. Trad. Hildegard Feist. São Paulo: Companhia das Letras, 2001.

ARMSTRONG, Karen. Maomé, uma biografia do profeta. Trad. Andréia Guerini et al. São Paulo: Companhia das Letras, 2002.

BETHENCOURT, Francisco \& Curto, Diogo Ramada (org.). A expansão marítima portuguesa, 1400-1800.Trad. Miguel Mata. Lisboa: Edições 70, 2010.

BOXER, Charles R. O império marítimo português: 1415-1825. Trad. Inês Silva Duarte. Lisboa: Edições 70, 2012.

CATZ, Rebecca. Fernão Mendes Pinto: sátira e anti-cruzada na Peregrinação. Lisboa: Instituto de Cultura e Lingua Portuguesa 1981.

CIDADE, Ernani. A literatura portuguesa e a expansão ultramarina. 2 ed. Coimbra: Arménio Amado editor, 1963. 


\section{Revista do SELL}

V. 5 , No. 4

ISSN: $1983-3873$

COLERIDGE, Henry James. The life and letters of Saint Francis Xavier. London: Burns and Oates, 1872 (2 vols.).

CONROD, Frédéric. "From the Roman Baroque to the Indian Jungle: Francis Xavier's Letters from Goa, or the Construction of a God", Laberinto Journal, n. 6, pp. 85-114, 2012.

DIDIER, Hugues. Francisco Xavier, pioneiro da inculturação. Trad. Denise Lolito. São Paulo: Paulinas, 1996.

FRÓIS, Luís. Europa Japão: um diálogo civilizacional no século XVI. Lisboa: Comissão Nacional para as Comemorações dos Descobrimentos Portugueses, 1993.

GRUNEBAUM, G. E. von. Classical Islam: A history, 600 A.D. to 1258 A.D. Trad. Katherine Watson. New Brunswick: Transaction Publishers, 2006.

JORGE, Carlos J. F. "A dimensão da pirataria na Peregrinação. Poder e contrapoder: uma ideologia da paródia", in: SEIXO, Maria Alzira e ZURBACH, Christine (org.). O discurso literário da "Peregrinação". Lisboa: Edições Cosmos, 1999.

LE GENTIL, C. Les portugais en Extrême Orient: Fernão Mendes Pinto, un précurseur de l'exotisme au XVle siècle. Paris: Hermann et Cie, 1947.

LEWIS, David Levering. O Islã e a formação da Europa: de 570 a 1215. Trad. Ana Ban. Barueri: Amarilys, 2010.

LIMA, Francisco Ferreira de. O outro livro das maravilhas: a Peregrinação de Fernão Mendes Pinto. Rio de Janeiro: Relume Dumará, 1998.

MARGARIDO, Alfredo. "Os relatos de naufrágios na Peregrinação de Fernão Mendes Pinto", in Estudos Portugueses: Homenagem a Luciana Stegagno-Picchio. Lisboa: Difel, 1991.

PINSKY, Jaime \& PINSKY, Carla B (org.). Faces do fanatismo. São Paulo: Contexto, 2004.

SCHILLING, Voltaire. Ocidente $x$ Islã: uma história do conflito milenar entre dois mundos. 3 ed. Porto Alegre: L\&PM, 2006.

SOUSA, Ivo Carneiro de. "A expansão otomana e a reacção portuguesa no reinado de D. Afonso V (1453-1481)", in: Os reinos ibéricos na ldade Média: livro de homenagem ao Prof. Dr. Humberto Carlos Baquero Moreno. Porto: Universidade do Porto, 2003.

TAVARES, Carla Margarida Martins. Identidade e alteridade na Peregrinação de Fernão Mendes Pinto. Dissertação de Mestrado. Universidade de Aveiro, 2008. 


\section{Revista do SELL}

V. 5 , No. 4

ISSN: $1983-3873$

WHEATCROFT, Andrew. Infiéis: o conflito entre a cristandade e o Islã (638-2002). Trad. Marcos José da Cunha. Rio de Janeiro: Imago, 2004. 